\section{DENTAL PUBLIC HEALTH}

\section{Influence of dental care systems on dental status. A comparison between two countries with different systems but similar living standards}

\section{Palmqvist S, Söderfeldt B et al. Community Dent Health 2001; 18: 16-19 \\ Despite demographic similarities, Sweden had a superior dental care system to Denmark.}

Questionnaires on their dental state were sent to random samples of 1175 Danish citizens (aged 45-69, response rate 73\%) and 1001 Swedish citizens (55-79, 67\%). Denmark has no public dental service (PDS) for adults, and the only specialties are orthodontics and oral surgery. Sweden has a PDS which competes with the private sector, and 8 specialties including periodontics and prosthodontics. Adult dental care costs about US $\$ 150$ per adult annually in both countries.

Edentulousness was similar in the Danish and the 10-yr-older Swedish cohorts $(6.2 \% ; 6.9 \%)$. Direct comparison of the 55-69 yr age groups in both countries showed edentulousness was commoner in Danes (9.4\% v.4.8\%), and that Swedes were far more likely to have fixed prostheses than Danes (14.1\% v. 3.6), who in turn were far more likely to have removable prostheses than Swedes (15.2\% v. 5.2\%).

\section{DENTAL RADIOLOGY}

\section{Potential risk for lead exposure in dental offices}

Chamberlain M, Bunge M et al. MMWR 2001; 50: 873-874

Lead-lined storage boxes for $\mathrm{x}$-ray films are dangerous and should be discarded.

In 2000, white lead oxide powder was discovered in boxes used to store intra-oral radiograph film, and all US health departments were alerted. In Wisconsin, radiation safety inspectors visited 240 of 2748 dental offices with radiograph equipment and found that 43 used such table-top lead-lined boxes. All boxes were found to contain a white powder in which 77\% was identified as lead oxide. Lead oxide contamination was also present in wall-mounted storage boxes.

A mock radiograph procedure indicated that over $3 \mathrm{mg}$ of lead might be transferred to a patient. As much as $30 \mathrm{mg}$ of lead could be retained on a stored packet of film. The authors warn of the dangers to children and pregnant women, advise that storage boxes are today unnecessary in view of much reduced scatter radiation, and suggest that unexplained high blood levels of lead may involve this route of exposure.

\section{ORAL SURGERY; BEHAVIOURAL SCIENCE}

\section{Depression, pain, exposure to stressful life events, and long-term outcomes in temporomandibular disorder patients}

Patients with myofascial pain dysfunction (MPD) had greater emotional dysfunction than patients with true organic disease of the temporomandibular joint (TMJ).

\section{Auerbach SM, Laskin DM et al. J Oral Maxillofac Surg 2001; 59: 628-633}

This study compared 130 patients with MPD, and 128 with true TMJ disease: 76 with internal derangement of the TMJ, 30 with MPD which had subsequently progressed to TMJ disease and 22 with degenerative TMJ arthritis. Subjects completed the Beck Depression Inventory (BDI), the Pain Disability Index (PDI) and the Social Readjustment Rating Scale (SRRS), prior to treatment.

BDI scores were significantly elevated before treatment. Subjects with MPD had higher scores on all 3 scales than those with internal derangement. After treatment, 15 MPD and 33 TMJ patients were followed up. PDI scores declined, and MPD patients showed a greater reduction than TMJ patients.

The authors discuss whether psychological intervention can be made more effective in patients with MPD where the pain is of muscular origin.

\section{TRAUMA}

\section{Prevalence of cervical spine injuries in patients with facial trauma

Hackl W, Hausberger K et al. Oral Surg 2001; 92: 370-376

Cervical spine injury occurred in 7\% of a large group of patients with facial trauma.

Over a 4 year period, 3083 patients aged 11-103 yrs were admitted to an Austrian hospital following facial trauma. Examination showed 206 to have a concomitant cervical spine injury (study group), and they were compared with 2877 controls who had facial trauma only.

Soft tissue injury occurred in about 70\% of each group, and fracture in around 35\%; dento-alveolar injury affected 8\% of the study group and 32\% of the controls; the pattern of injuries did not differ significantly, however.

The study group was significantly older (mean 42 v. 34 yrs) than the controls, more had sustained a traffic accident (44\% v. $20 \%$ ), fewer had sports injuries (23\% v. 37\%), fewer had dentoalveolar injury (8\% v. $32 \%)$ and more had a brain injury $(22 \% \mathrm{v}$. $9 \%$ ). The authors caution that cervical spine injury is easy to miss, and recommend a CT scan where it is suspected. 